\title{
EDUCAR E ENSINAR NA PEDAGOGIA MARXISTA: A FORMAÇÃO DA SEGUNDA NATUREZA
}

\author{
José Luiz Zanella ${ }^{1}$ \\ "O homem é toda uma formação \\ histórica, obtida mediante coerção"
}

(GRAMSCI).

\section{RESUMO:}

O objetivo deste artigo é apresentar algumas contribuições da pedagogia marxista para a explicação do problema da "falta de limites" dos alunos da educação básica. Analisa que a falta de limites não é uma decorrência da natureza humana; ao contrário, mostra que não há uma natureza humana, fixa, eterna. O homem não nasce homem, torna-se homem e seu ser é uma formação histórica, produzida pelo trabalho e educação. Para formar o aluno concreto há a necessidade de um processo educativo que tem, na formação para o trabalho concreto, sua centralidade. Educar é um aprendizado que requer, na primeira fase de desenvolvimento da criança, a disciplina externa para a formação dos hábitos que, uma vez fixados, constituirão a segunda natureza. A partir desse processo, na segunda fase, passase do automatismo à liberdade, resultando numa disciplina interna em que "autodisciplina intelectual e autonomia moral" formam o caráter. Por fim, mostra que ensino é educação, explicitando aí a concepção marxista de educação na formação do homem omnilaterial que, para realiza-se concretamente necessita lutar pela superação da sociedade capitalista e por uma educação para além do capital.

Palavras-chave: Educar, segunda natureza, pedagogia marxista

\section{EDUCATE AND TEACH IN MARXIST PEDAGOGY: THE FORMATION OF THE SECOND NATURE}

ABSTRACT:

The objective of this article is present some contributions for the marxist pedagogy in order to explain the problem of lacking of limits occured among schollboys of the basic educational schools. It analyses that the lacking of limits does not occur because of the human nature, on the contrary, it shows that there is not a fixed, eternal human nature. Man does not born man. Becomes man and his being is an historical formation, produced by work and education. To form a concrete schoolboy is necessary an educative process that has, in the formation for work, its central point. To educate is an apprenticeship that requeres, in the first phase of the child development, the external discipline for the formation of habits, which, once estabilished, will constitute a second nature. Since then, this process, in the second phase, will pass from an automatism to liberty, resulting in an internal discipline in which intellectual self-discipline and moral autonomy will form the character. Finally, this article shows that teching is education, explicating that the marxist concept of education in the formation omnilateral of man, who in order to win himself concretely will need to struggle for superate the capitalist society and for an education beyond the capital.

Keywords: To educate, second nature, Marxist pedagogy 


\title{
Introdução
}

Buscamos, neste texto apresentar algumas contribuições da pedagogia marxista ${ }^{2}$ para o entendimento e explicação do problema da "falta de limites" dos alunos e possíveis contribuições para superação desse problema. Conduziremos nossa reflexão a partir destas questões: Como a pedagogia marxista analisa esta problemática e que encaminhamento apresenta? O que é a segunda natureza e como é produzida pelo trabalho e pela educação? Como educar e ensinar alunos que possuem, de certa forma, uma "segunda natureza" já formada, ou, em que medida é possível o reeducar e como fazê-lo a partir das condições dadas?

Com base nessas indagações, organizamos o texto em três partes. Na primeira, apresentamos uma breve crítica às concepções metafísicas e empíricas de aluno, tendo em vista a compreensão do aluno como um sujeito concreto - histórico e social. Destaca-se aí a centralidade do trabalho na formação do homem. Na segunda parte, mostramos a necessidade do educar relacionado ao trabalho explicitando em que consiste a segunda natureza. Por fim, explicitamos a relação ensino e educação destacando que ensino é também educação.

Esperamos, com esta reflexão, contribuir na superação de um possível distanciamento entre a teoria e o que acontece nas salas de aula, dito da seguinte forma por Libâneo (2008):

\begin{abstract}
Minha tese inicial é bastante pessimista: há uma distância considerável entre as políticas educacionais, a legislação educacional, a pesquisa acadêmica, e o que o acontece na realidade das escolas, isto é, no ensino, no trabalho cotidiano dos professores, na aprendizagem dos alunos. Esse distanciamento das questões mais concretas da sala de aula e do trabalho direto dos professores com os alunos é um forte indício da desatenção, do desapreço, com os aspectos pedagógico-didáticos que, em última instância, são os que efetivamente atuam na aprendizagem dos alunos e no trabalho dos professores. Paradoxalmente, é na ponta do sistema de ensino, nas escolas e nas salas de aula, que as coisas efetivamente acontecem, é lá que sabemos o que os alunos aprendem, como aprendem e o que fazem com o que aprendem (LIBÃNEO, 2008, pp. 1 e 2).
\end{abstract}

Observa-se a necessidade de uma "educação das consciências" para que a teoria marxista, em sua historicidade, seja assimilada pelos professores sem cairem no risco do recuo da teoria e sem, por outro lado, cairem no risco do pragmatismo. Talvez uma das mediações para a assimilação da teoria esteja no desafio de dialogar com o bom senso das problemáticas vivenciadas pelos professores, fazendo a "conversão do saber objetivo [pedagogia marxista] em saber escolar, de modo que se torne assimilável pelos alunos [professores] no espaço e tempo escolares" (SAVIANI, 2003, p. 9).

A teoria em si (...) não transforma o mundo. Pode contribuir para sua transformação, mas para isso tem que sair de si mesma, e, em primeiro lugar, tem que ser assimilada pelos que vão ocasionar, com seus atos reais, efetivos, tal transformação. Entre a teoria e a atividade prática transformadora se insere um trabalho de educação das consciências, de organização dos meios materiais e planos concretos de ação; tudo isso como passagem indispensável para desenvolver ações reais, efetivas. Nesse sentido, uma teoria é prática na medida em que materializa, através de uma série de mediações, o que antes só existia idealmente, como 
conhecimento da realidade ou antecipação ideal de sua transformação (VÁZQUEZ, 1968, pp. 206 e 207).

Portanto, esta é uma reflexão destinada aos professores da educação básica que, pelas condições precárias de trabalho e de formação, na maioria dos casos, não têm o conhecimento da pedagogia marxista e o acesso a pesquisas nesta área.

\section{A formação do ser social: a superação da concepção abstrata e empírica e a defesa do sujeito concreto}

Quem é este sujeito que precisa ser formado? Os alunos "sem limites" são o que são por possuírem uma natureza violenta que vem desde o nascimento? Ou faltou uma educação severa que, a partir de uma essência verdadeira de ser humano, fizessem-nos educados? Ou, seriam estes alunos a expressão do conjunto de relações sociais em que estão inseridos?

Saviani (2009) afirma que uma das tarefas dos educadores do campo marxista é "empreender a critica à educação burguesa evidenciando seus mecanismos e desmistificando sua justificação ideológica" (p.114). Passemos, portanto, rapidamente, à crítica às duas concepções hegemônicas de formação humana: a concepção essencialista da pedagogia tradicional e a concepção existencialista da pedagogia da escola nova.

A pedagogia tradicional caracterizou-se pela autoridade, severidade e coerção. A criança era concebida como um adulto em miniatura. Educar consistia em moldar a criança a partir de um modelo de ser humano (essência).

A educação deve formar o homem de acordo com uma finalidade previamente estabelecida. A noção de Natureza do autor [Comenius] não tem significado empírico na acepção que só considera o homem tal como é concretamente. Escreve Comenius: 'Por Natureza não entendemos a corrupção que, a partir da Queda, atingiu todos os homens ... mas o nosso sistema espiritual original e essencial, ao qual devemos ser conduzidos como a um estado preliminar'. Assim entendida, a Natureza constitui a 'verdadeira' essência do homem que, embora exista no homem empírico, não pode nas condições de vida concreta desenvolver-se plenamente, pois se encontra asfixiada pela 'corrupção que nos atingiu'. A educação deve, tal como proclamava há séculos a pedagogia da essência, dar a sua contribuição de modo que a verdadeira essência humana possa assenhorear-se dos homens concretos (...)"(SUCHODOLSKI, 2000, pp. 26 e 27, grifos nossos).

O mérito da pedagogia tradicional foi a formação de alunos disciplinados, responsáveis, que cultivavam o respeito; porém, fazia-o de tal forma que destruía a iniciativa e criatividade da criança.

Em reação à severidade da pedagogia tradicional que anulava a criança, teve início, ainda na modernidade, a "concepção humanista moderna" (Saviani, 1987), com destaque no século XX, para a pedagogia da escola nova. Nesta concepção, educar consistia em respeitar as necessidades e interesses da criança, oferecendo condições adequadas, amor, carinho e atenção.

Provar que 'é bom tudo o que sai das mãos do criador da Natureza e tudo degenera nas mãos do homem' [afirmava Rousseau]. Posto isto, será possível confiar aos homens o problema da educação? Não será conveniente dar à criança a possibilidade de um desenvolvimento livre e 
espontâneo? A educação - segundo Rousseau - não deve ter por objetivo a preparação da criança com vista ao futuro ou modelá-la de determinado modo; deve ser a própria vida da criança. (...) A criança é a própria fonte da educação. É a partir do desenvolvimento concreto da criança, das suas necessidades e de seus impulsos, dos seus sentimentos e dos seus pensamentos, que se forma o que ela há de vir a ser, graças ao auxílio inteligente do mestre (SUCHODOLSKI, 2000, pp. 32 e 33, grifos nossos).

Temos ai uma concepção empírica de criança que deu origem à uma educação espontaneísta. A criança é o "pai" do adulto. Nasce boa, pura e "a natureza humana tende a se realizar a si mesma" (TEIXEIRA, 2000 p. 19). Assim Saviani sintetiza a concepção de criança empírica:

Sujeitos singulares que se distinguem uns dos outros pela sua originalidade, criatividade e autonomia, constituindo-se no centro do processo educativo. Por esse caminho a pedagogia nova elide a história, naturalizando as relações sociais, como se os educandos pudessem se desenvolver simplesmente a partir de suas disposições internas, de suas capacidade naturais, inscritas em seu código genético (SAVIANI, 2005, p. 45).

Gramsci faz a seguinte crítica a essas concepções metafísica e empírica de criança as quais podem estar na origem do problema de falta de limites:

Tenho a impressão de que a tua concepção [refere-se a sua mulher que está na URSS], bem como a dos outros membros da família, é demasiado metafísica [concepção abstrata], isto é, pressupõe que no menino esteja já em potência todo o homem e que se deve ajudá-lo a desenvolver aquilo que já contém de forma latente, sem coerções, deixando agir as forças espontâneas da natureza [concepção empírica] ou que sei eu. Eu penso, ao contrário, que o homem é toda uma formação histórica, obtida mediante coerção (entendida não apenas no sentido brutal e de violência externa) [concepção concreta] e penso unicamente isso; que de outro modo cair-se-ia em uma forma de transcendência ou de imanência. (GRAMSCI, apud MANACORDA, 1990, p. 74, grifos nossos).

Ao contrário dessas duas concepções de criança, a pedagogia marxista postula uma concepção histórica, social, concreta de criança. Daí o postulado de Gramsci "o homem é toda uma formação histórica, obtida mediante coerção". Tal concepção é coerente com o que afirma Marx: "a essência humana não é abstrato residindo no indivíduo único. Em sua efetividade é o conjunto das relações sociais" (MARX, 1987, p.162, grifos nossos).

Significa que o homem não nasce homem. "O homem (...) não é, por natureza, nem bom, nem mau; nem benevolente, nem malevolente, nem altruísta nem egoísta; nem sublime nem bestial etc". (MÉSZÁROS, 2006, p. 151). Poderíamos acrescentar, nem educado e nem sem falta de limites. Ao nascermos, temos, por assim dizer, nossa primeira natureza que é o corpo, mas não temos ainda a segunda natureza que é nossa identidade. Esta segunda natureza tem de ser produzida historicamente pelo trabalho e pela educação. "Na visão de Marx, o homem (...) se torna, por sua própria atividade, aquilo que é num determinado momento" (MÉSZÁROS, 2006, p. 137). Tornar-se homem é um trabalho educativo que tem na centralidade do trabalho concreto sua base de constituição da segunda natureza. 
A pedagogia marxista concebe o homem como um conjunto das relações sociais, pois o trabalho é a base da vida humana. O trabalho "é a condição básica e fundamental de toda a vida humana. E em tal grau que, até certo ponto, podemos afirmar que o trabalho criou o próprio homem" (ENGELS, 2004, p. 13). Nas palavras de Saviani (2007): "A essência humana é produzida pelos próprios homens. O que o homem é, é-o pelo trabalho" (p.154). Agindo sobre a natureza mediante o processo de trabalho, o homem também se modifica, se faz homem, se humaniza. "Atuando assim sobre a natureza externa e modificando-a, ao mesmo tempo modifica sua própria natureza. Desenvolve as potencialidades nela adormecidas e submete ao seu domínio o jogo das forças naturais" (MARX, 1999, p. 211).

Marx entende o homem como um ser natural/histórico ao mesmo tempo. "O homem é imediatamente ser natural. Como ser natural, e como ser natural vivo, está, em parte, dotado de forças naturais, de forças vitais, é um ser natural ativo" (MARX, 1987, p. 206). Todavia, o homem, "não é apenas ser natural, mas ser natural humano, isto é, um ser que é para si próprio e, por isso, ser genérico, que enquanto tal deve atuar e confirmar-se tanto em seu ser como em seu saber" (p. 207). Portanto, o homem é sua própria natureza humanizada. Essa humanização da natureza humana dá-se mediante o processo de trabalho. "A formação dos cinco sentidos é um trabalho de toda a história universal até nossos dias" (p. 178). Afirma Marx: "O olho fez-se um olho humano, assim como seu objeto se tornou um objeto social, humano, vindo do homem para o homem. Os sentidos fizeram-se assim imediatamente teóricos em sua prática" (p. 177). E conclui Marx: "toda a assim chamada história universal nada mais é do que a produção do homem pelo trabalho humano [...]" (p. 181).

A individualidade humana não está dada a priori como se fizesse parte de uma natureza humana acabada. Ao contrário, a natureza humana é histórica, entendendo a história como devir. Assim, "a humanidade que se reflete em cada individualidade é composta de diversos elementos: 1) o indivíduo; 2) os outros homens; 3) a natureza" (GRAMSCI, 1999, p. 413). Significa que a individualidade humana é construída a partir das relações orgânicas que o homem estabelece com os outros homens e com a natureza.

Resulta que o homem é uma formação histórica a qual denominamos de segunda natureza. Advém aqui o princípio educativo do trabalho.

Se a existência humana não é garantida pela natureza, não é uma dádiva natural, mas tem de ser produzida pelos próprios homens, sendo, pois, um produto do trabalho, isso significa que o homem não nasce homem. Ele forma-se homem. Ele não nasce sabendo produzir-se como homem. Ele necessita aprender a ser homem, precisa aprender a produzir sua própria existência. Portanto, a produção do homem é, ao mesmo tempo, a formação do homem, isto é, um processo educativo. A origem da educação coincide, então, com a origem do homem mesmo. (SAVIANI, 2007, p. 154, grifos nossos).

Trata-se de recuperar o significado profundo da categoria trabalho na constituição histórica do "ser" homem que busca incessantemente humanizar-se a partir da satisfação das necessidades imediatas (satisfação dos meios imprescindíveis à manutenção da vida reino da necessidade) e, principalmente, na satisfação das necessidades propriamente humanas (reino da liberdade - cultura, arte, ciência, filosofia...). 
Esse é o trabalho concreto, trabalho útil; é "aquele cuja utilidade se patenteia no valor-de-uso do seu produto ou cujo produto é um valor-de-uso" (MARX, 1999, p. 63). Nesse sentido, o trabalho é positividade, é realizador da vida humana.

O processo de trabalho (...) é atividade dirigida com o fim de criar valores-de-uso, de apropriar os elementos naturais às necessidades humanas; é a condição necessária do intercâmbio material entre o homem e a natureza; é condição natural eterna da vida humana, sem depender, portanto, de qualquer forma dessa vida, sendo antes comum a todas as suas formas sociais. (MARX, 1999, p. 218).

Porém, como observa Marx (1999), o trabalho é realizado pelo homem que é sempre um ser social e histórico. Em cada modo de produção há uma dialética entre trabalho realizador da vida e trabalho como negatividade - escravo, servil, assalariado. $\mathrm{O}$ que

Os homens são decorre diretamente do modo como eles produzem sua existência. Em consequiência, o modo de produção determina todas as manifestações de existência humana, desde as formas da produção dos bens materiais destinados ao consumo e à troca, até as formas de consciência (SAVIANI, 2009, p.111).

Em nosso tempo, a sociedade capitalista - com sua lógica da mercadoria e da acumulação - constitui-se numa prática social educativa. Quando a teoria da pedagogia espontaneista afirma a individualidade da criança e a tendência desta desenvolver-se naturalmente sem a autoridade de um educador, está permitindo que a sociedade eduque a criança. Pois, "a consciência da criança não é algo 'individual', é o reflexo da fração da sociedade civil de que participa a criança, das relações sociais tais como elas se encontram na família, na vizinhança, na aldeia, etc." (GRAMASCI, apud MANACORDA, 1990, p. 245).

O ambiente (o meio) é um poderoso educador. A criança não tem capacidade para discernir sobre o que é importante para sua formação no sentido do "aluno concreto". Tende a extrair do meio tudo o que for interessante, agradável, fácil e negar tudo o que for trabalhoso, difícil... De modo que não há espontaneidade na educação na criança. Se o adulto não educar, o meio o fará e de forma autoritária.

Portanto, "renunciar a formar a criança significa apenas permitir que sua personalidade se desenvolva extraindo caoticamente do ambiente geral todos os motivos de vida" (GRAMSCI, apud MANACORDA, 1990, p. 75). E, ainda,

Toda atitude de respeito à espontaneidade, em sua aparência de respeito pela natureza da criança, é, na realidade, renúncia a educar, a formar o homem segundo um plano humano; é o abandono completo da criança ao autoritarismo, ou seja, à pressão exercida objetivamente pelo ambiente (MANACORDA, 1990, p. 75).

Podemos inferir que, de certo modo, as crianças sem limites foram educadas pelo meio, pela sociedade capitalista. Há um ethos assentado numa ética permissiva, hedonista, 
de consumo, de culto ao prazer, ao corpo-objeto, ao imediato, da indiferença e do relativismo de tudo, em detrimento dos valores do coletivo, do esforço, da disciplina, da austeridade. Tem aprovação ética o que for rápido, eficiente e lucrativo. "A celebração do eu explica o fascínio pelas celebridades, por atores e atrizes, por modelos e pop-stars. O banal, o frívolo, o inútil são a água de banho das novas gerações, desde a mais tenra idade" (GOERGEN, 2005, p. 79). É uma educação de "adestramento social" que "internaliza" conceitos e valores do sistema do capital.

Faz-se necessário, portanto, a intervenção da educação ou do trabalho educativo. Coloca-se aqui o desafio de educar.

\section{O educar e a formação da segunda natureza}

O aluno concreto, como síntese das relações sociais, vive em condições que não escolheu. É um ser social, um "animal político" e "aquele que for incapaz de viver em sociedade, ou que não tiver necessidade disso por ser auto-suficiente, será uma besta ou um deus" (ARISTÓTELES, 1999, p. 147). Por isso a necessidade do trabalho educativo. "O trabalho educativo é o ato de produzir, direta e intencionalmente, em cada indivíduo singular, a humanidade que é produzida histórica e coletivamente pelo conjunto dos homens" (SAVIANI, 1996, p. 147).

Com base nos pressupostos da filosofia marxista, Saviani explica em que consiste o aluno concreto, em oposição ao aluno empírico em relação à necessidade de aquisição do conhecimento sistematizado.

O aluno empírico pode querer determinadas coisas, pode ter interesses que não necessariamente correspondem aos seus interesses, enquanto aluno concreto. É neste âmbito que se situa o problema do conhecimento sistematizado, que é produzido historicamente e, de certa forma, integra o conjunto dos meios de produção. Esse conhecimento sistematizado pode não ser de interesse do aluno empírico, ou seja, o aluno, em termos imediatos, pode não ter interesse no domínio desse conhecimento; mas ele corresponde diretamente aos interesses do aluno concreto, pois enquanto síntese das relações sociais, o aluno está situado numa sociedade que põe a exigência do domínio deste tipo de conhecimento. E é, sem dúvida, tarefa precípua da escola viabilizar o acesso a este tipo de saber (SAVIANI. 2003, pp. 143 e 144).

A educação, para Saviani (1996), é uma decorrência da luta do homem na transformação da natureza para produzir sua existência. Este processo histórico produziu o mundo da cultura, o mundo humano. Ao produzir bens materiais, o homem produz bens não-materiais: ciência, filosofia, arte. Enfim,

É a produção de idéias, conceitos, valores, símbolos, hábitos, atitudes, habilidades. Numa palavra, trata-se da produção do saber, seja do saber sobre a natureza, seja do saber sobre a cultura, isto é, o conjunto da produção humana. Obviamente a educação se situa nessa categoria de trabalho não-material" (SAVIANI, 1996, p. 146).

Quando os bens não-materiais são tomados como algo exterior ao homem, são objetos de estudos das ciências humanas. Porém, quando os bens não-materias são tomados como algo necessário à formação humana, ou seja, como mediação educativa, então, temos aí a especificidade da educação. "Do ponto de vista da educação, ou seja, da perspectiva da pedagogia entendida como ciência da educação, esses elementos [idéias, conceitos, 
valores, símbolos, hábitos, atitudes, habilidades] interessam enquanto é necessário que os homens os assimilem, tendo em vista a constituição de algo como uma segunda natureza" (Idem, p. 147).

A segunda natureza é a concretização de uma aprendizagem obtida por um processo coercetivo no sentido da exigência de um "trabalho" de formação do hábito. É uma prática na qual "nos tornamos perfeito pelo hábito (...) tornamo-nos justos praticando atos justos (...)" (ARISTÓTELES, 1991, p. 27). E que seria o hábito? "Adquirir um habitus significa criar uma situação irreversível. Para isso, porém, é preciso ter insistência e persistência; faz-se mister repetir muitas vezes determinados atos até que eles se fixem" (SAVIANI, 2003, p. 21). E adquirir um habitus é adquirir uma disposição permanente em que "o objeto da aprendizagem se converte numa espécie de segunda natureza (Idem, 2003, p. 20).

Saviani (2003) cita como exemplo de segunda natureza o processo de aprender a dirigir automóvel e de alfabetização. Em ambos os casos, a aprendizagem passou pelo "automatismo" = repetição, hábito, disciplina e esforço até o conteúdo (conceitos e habilidades) fixarem-se no sujeito. Uma vez fixado o processo, temos a realização da aprendizagem - segunda natureza, a qual torna o sujeito livre. Portanto, "o automatismo é condição da liberdade" (Ibidem, 2003, pp. 18 e 19).

O educar (intencional ou pelo meio) é a formação da segunda natureza que, uma vez formada, torna-se difícil ser modificada. Por tal razão, Gramsci (2000), Manacorda (1990) e Makarenko (2002) são unânimes em afirmar a necessidade da intervenção educativa na mais tenra idade. Gramsci afirma que o educar deve ocorrer antes da puberdade, ou seja, até os 15 anos. Makarenko afirma: "as bases fundamentais da educação são construidas até os cinco anos" (2002, p. 335). Com base em Gramsci (apud Manacorda, 1990), elaboramos o quadro abaixo sobre as duas fases do processo educativo, as quais combinam dialeticamente automatismo e liberdade.

Quadro I: As duas fases do processo educativo

\begin{tabular}{|l|l|}
\hline Antes da puberdade & Depois da puberdade \\
\hline O educar é possível & O reeducar é difícil \\
\hline Pedagogia da exigência - coerção & Pedagogia da criatividade/liberdade \\
\hline $\begin{array}{l}\text { Disciplina externa (impositiva, coercetiva) } \\
\text { para formar os hábitos (força de vontade, } \\
\text { o amor à disciplina e ao trabalho, a } \\
\text { constância dos objetivos). }\end{array}$ & $\begin{array}{l}\text { Disciplina interna } \\
\text { moral". }\end{array}$ \\
\hline $\begin{array}{l}\text { Ser severo de forma carinhosa } \\
\text { (Makarenko): "a aquisição dos hábitos de } \\
\text { disciplina e todo o estímulo exercido }\end{array}$ & $\begin{array}{l}\text { Educação = segunda natureza. Produziu- } \\
\text { se no indivíduo, a humanidade que é } \\
\text { produzida histórica e coletivamente. }\end{array}$ \\
$\begin{array}{l}\text { sobre a criança pelos adultos devem } \\
\text { todavia ocorrer 'sem mortificar a a } \\
\text { espontaneidade` da criança" (Manacorda) }\end{array}$ & \\
\hline $\begin{array}{l}\text { Automação/repetição = habitus = } \\
\text { disposição permanente e irreversível. }\end{array}$ & Autonomia \\
Heteronomia & Formou-se a segunda natureza=educação. \\
\hline
\end{tabular}

Fonte: Organização do autor (2010).

Portanto, o educar passa pela aprendizagem do trabalho, pois, "o que o homem é, éo pelo trabalho" (SAVIANI, 2007, p. 154). 
Em uma sociedade racional, qualquer criança deve ser um trabalhador produtivo a partir dos nove anos, da mesma forma que um adulto em posse de todos os seus meios, não pode escapar da lei da natureza, segundo a qual aquele que quer comer tem de trabalhar, não só com o seu cérebro, mas também com suas mãos (Marx, 1976, pp. 60, grifos nossos).

Entre os autores da pedagogia marxista, além de Gramsci (2000), destacam-se Makarenko (1976, 2002 e 2005) e Pistrak (2003) no desenvolvimento de uma pedagogia do trabalho como mediação da formação do ser social. Advertimos que não se trata de reduzir o trabalho a um recurso didático do método do aprender a aprender. Ao contrário, nos referimos aqui ao trabalho como principio educativo no sentido do trabalho pedagógico, assim explicitado por Saviani:

Num primeiro sentido, o trabalho é princípio educativo na medida em que determina, pelo grau de desenvolvimento social atingido historicamente, o modo de ser da educação em seu conjunto. Nesse sentido, aos modos de produção correspondem modos distintos de educar com uma correspondente forma dominante de educação. E um segundo sentido, o trabalho é princípio educativo na medida em que coloca exigências específicas que o processo educativo deve preencher, em vista da participação direta dos membros da sociedade no trabalho socialmente produtivo. Finalmente, o trabalho é princípio educativo num terceiro sentido, à medida que determina a educação como uma modalidade específica e diferenciada de trabalho: o trabalho pedagógico (SAVIANI, 1989, p. 1-2).

Makarenko ${ }^{5}$ enfatiza a necessidade de educar a criança para o trabalho. Recomenda um método de "imposição não mecânica" (coerção = ser severo de forma carinhosa, filosofia do meio-termo) que requer uma organização familiar que tenha planejamento e ordem (definição de regras) que possibilitem à criança assumir as tarefas por tempo prolongado e por conta própria com responsabilidade. É preciso despertar na criança o gosto pelo trabalho através do interesse "técnico" (como funciona, sentir a necessidade e utilidade). Exemplos de trabalhos que podem ser feitos por crianças de acordo com a idade e contexto da família: regar as flores, limpar o pó, passar pano na calçada, pôr a mesa antes da refeição, dar de comer aos animais de estimação, ser responsável pela compra de certos produtos etc.

Pistrak (2003), ao referir-se às diferentes formas de trabalho que a escola pode executar, mostra a importância do trabalho doméstico desde que se identifique aquele trabalho que possibilita a formação de hábitos. O critério é o valor social e que se desenvolva o amor pelo trabalho.

A higiene pessoal (trato do corpo, dos dentes, das roupas, da cama, dos livros, da caneta, etc.) deve-se tornar um hábito, uma coisa essencial, sem a qual não se possa viver, um hábito tão sólido que seja impossível voltar à sujeira, às condições de vida anti-sanitárias (PISTRAK, 2003, p. 52).

Esse é o sentido do trabalho como principio educativo na formação do sujeito. Esse sentido, de certo modo, é usual ao senso comum em seu bom senso quando afirma ser necessário ensinar a criança a trabalhar para que ela saiba dar "valor" às coisas, isto é, 
saber de onde vêm, quanto custaram. Está aí o valor do trabalho. É o trabalho que cria o valor e valor é quantidade de trabalho.

Portanto, temos o trabalho concreto como formador do ser humano. Mas para trabalhar é preciso aprender. Frigotto (2002), interpretando Marx, mostra em que consiste o "princípio educativo do trabalho" como direito e dever.

O trabalho (...) por ser elemento criador da vida humana (...) [constituise em] um dever a ser apreendido, socializado, desde a infância. Tratase de apreender que o ser humano - como ser natural - necessita elaborar a natureza, transformá-la, e pelo trabalho extrair dela bens úteis para satisfazer as suas necessidades vitais e socioculturais. Quando não se socializa este valor, a criança e o jovem tornam-se, no dizer de Gramsci, espécies de mamíferos de luxo, que acham natural viverem do trabalho e da exploração dos outros. Não se trata aqui de defender a exploração capitalista do trabalho infanto-juvenil, que mutila e degrada a vida da infância e da juventude. Trata-se de educar a criança e o jovem para participar das tarefas da produção, de cuidar de sua própria vida e da vida coletiva e para partilhar de tarefas compatíveis com sua idade (...).

Porém, o trabalho e a propriedade dos bens do mundo são um direito, pois é por eles que os indivíduos podem criar, recriar e reproduzir permanentemente sua existência. Impedir o direito ao trabalho, mesmo em sua forma capitalista de trabalho alienado, é uma violência contra a possibilidade de produzir minimamente a própria vida e, quando for o caso, a dos filhos. Assim, a propriedade privada que impede o acesso ou a produção dos bens para a produção da vida é uma violência e algo humanamente insustentável. A distinção do trabalho, da propriedade e da tecnologia como valores de uso e de troca é fundamental para entendermos os desafios que se apresentam à humanidade nos dias atuais (FRIGOTTO, 2002, pp. 14- 15, grifos nossos).

As consequências da negação do dever e do direito ao trabalho constituem-se, na expressão de Gramsci, na criação de "mamíferos de luxo", ou, nos dias atuais, de crianças sem limites. A citação a seguir ilustra como se produz a criança sem limites.

Eu sou engenheiro e ela (mãe) é professora. Nosso filho era um bom garoto, mas agora não sabemos o que se passa com ele. Diz grosserias a sua mãe, sai de casa quando lhe dá vontade e nos desaparecem coisas. Que fazer? Educamos e demos a ele atenção como se deve, sempre teve tantos brinquedos quantos quis, vestimos e calçamos, tem um quarto só para ele e lhe proporcionamos todo tipo de distrações. Agora (tem 15 anos), não the proibimos que vá ao cinema ou ao teatro. Se ele deseja uma bicicleta, a compramos. De nossa parte, você está vendo: somos pessoas normais de quem não pode ter herdado nada de mal. Por que então, o meu filho é tão mau?".

- Você faz a cama do garoto? Sempre? - perguntei à mãe.

- Sempre.

- Nunca lhe ocorreu propor-lhe que ele mesmo a faça?

Perguntei ao pai:

- Você limpa os sapatos de seu filho?

- Sim.

Terminei a conversa dizendo-lhes: 
- Vão tranqüilos e não procurem mais ninguém. Sentem-se em qualquer banco solitário de algum jardim e tratem de recordar o que fizeram com seu filho. Perguntem a si mesmo quem tem a culpa de que o garoto seja assim e encontrarão a resposta e os procedimentos para corrigi-lo (MAKARENKO, 2002, p. 330).

Portanto, para a pedagogia, marxista educar o ser humano, é produzi-lo a partir do trabalho concreto o qual requer uma organização com regras. Tal organização pode ser a "família", a escola, ou outras instituições, as quais, consoante afirmado acima, são determinadas pelo modo de produção. Na pedagogia marxista, a educação para o trabalho não é um adestramento para o trabalho assalariado e nem uma forma de exploração do trabalho infantil. Ao contrário, é uma resistência à autoalienação do trabalho.

O educar a partir do trabalho concreto não está suspenso no ar. Constitui-se em resistência concreta que se torna mais consciente nas lutas dos trabalhadores pela superação do trabalho assalariado e da lógica educativa do capital. É nas contradições da prática social que se coloca a disputa por projetos educativos.

Não há nenhuma atividade humana da qual se possa excluir qualquer intervenção intelectual - o Homo faber não pode ser separado do Homo sapies. Além disso, fora do trabalho, todo homem desenvolve alguma atividade intelectual; ele é, em outras palavras, um 'filósofo', um artista, um homem com sensibilidade; ele partilha uma concepção do mundo, tem uma linha consciente de conduta moral, e portanto contribui para manter ou mudar a concepção de mundo, isto é, para estimular novas formas de pensamento (GRAMSCI, apud MÉSZÁROS, 2005, p. 49).

O desafio é uma educação para o trabalho que rompa com a autoalienação do trabalho e que permita, ao mesmo tempo, lutar pela universalização do trabalho e da educação. O capital, segundo Mészáros (2005), não consegue apropriar-se da concepção de mundo coletiva e dos sujeitos concretos a não ser através de sua racionalidade nas instituições formais. Por essa razão, no âmbito da prática social, há espaço para uma mudança essencial em que "a questão fundamental é a necessidade de modificar, de forma douradora, o modo de internalização históricamente prevalecente" (Idem, p. 52).

É com base nessa concepção mais ampla de educação que se pode realizar uma "reforma radical" na educação formal.

Se, entretanto, os elementos progressistas da educação formal forem bem sucedidos em redefinir a sua tarefa num espírito orientado em direção à perspectiva de uma alternativa hegemônica à ordem existente, eles poderão dar uma contribuição vital para romper a lógica do capital, não só no seu próprio e mais limitado domínio como também na sociedade como um todo (MÉSZÁROS, 2005, p. 59).

Torna-se evidente a importância da educação formal e do desafio do educar emancipatório nesse âmbito. 


\section{Ensino é educação?}

O educar no sentido da formação da segunda natureza, tem início na "família" (Makarenko, 1976) e tem continuidade por toda a vida. Portanto, embora a educação ministrada pelos pais ou responsáveis seja imprescindível e fundamental, não é correto afirmar que a tarefa da escola é somente ensinar e educar é tarefa exclusiva da família.

Para a pedagogia marxista ensino também é educação. "Se a educação não se reduz ao ensino, é certo, entretanto, que ensino é educação e, como tal, participa da natureza própria do fenômeno educativo" (SAVIANI, 2003, p. 12). Segundo GRAMSCI (2000), na escola tradicional, "a própria organização dava a educação", através do estudo do latim (morto vivo). O latim educava porque possibilitava a formação cultural, mediante aquisição de hábitos de ordem, de disciplina e de trabalho e, por conseguinte, possibilitava ao jovem a aquisição de "uma intuição historicista do mundo e da vida, que se torna uma segunda natureza" (p. 48). Instrução (ensino do conteúdo concreto) é educação e o estudo "deve ser formativo, ainda que instrutivo, isto é, rico de noções concretas" (GRAMSCI, 2000, p. 49).

Lida-se com adolescentes, aos quais é preciso fazer com que adquiram certos hábitos de deligência, de exatidão, de compostura até mesmo física, de concentração psíquica em determinados assuntos, que só se podem adquirir mediante uma repetição mecânica de atos disciplinados e metódicos. Um estudioso de quarenta anos seria capaz de passar dezesseis horas seguidas numa mesa de trabalho se, desde menino, não tivesse assimilado, por meio de coação mecânica, os hábitos psico-físicos apropriados? (Idem, p. 46).

Continua Gramsci, enfatizando que o nexo instrução-educação na escola,

somente pode ser representado pelo trabalho vivo do professor, na medida em que o professor é consciente do contraste entre o tipo de sociedade e de cultura que ele representa e o tipo de sociedade e cultura representado pelos alunos; e é também consciente de sua tarefa, que consiste em acelerar e disciplinar a formação da criança conforme o tipo superior em luta com o tipo inferior (Ibidem, p. 44).

Segundo Gramsci, porém, o nexo instrução-educação não é um problema somente de programas e dos professores enquanto indivíduos, mas "de todo o complexo social do qual os homens são expressão" (p. 45). Significa que o professor concreto é, de um lado, expressão das relações sociais capitalistas e, de outro, pode ser expressão de um intelectual orgânico dos interesses dos trabalhadores na medida em que esse profissional seja consciente de que sua tarefa de educador desenvolva nos educandos o "bom senso" presente no senso comum para elevá-los à cultura elaborada, mais desenvolvida produzida pela humanidade, na perspectiva da superação do modo de produção capitalista. É nesse sentido que a escola torna-se ligada à vida e o ensino deixa de ser abstrato, formal, mecânico.

Manacorda (1991), ao interpretar a proposta de ensino e de escola de Marx, o qual, em algumas passagens, enfatiza que caberia à escola somente o ensino de noções exatas, sem relação com conclusões pessoais, mostra que isso não corresponde com à totalidade de seu pensamento sobre educação.

Não quer dizer em absoluto exclusão da validade do que não seja aprendizagem de noções exatas, pois Marx coloca todo esse processo de 


\begin{abstract}
‘educação' verdadeira e autêntica na própria vida onde as crianças se integram aos adultos; se acrescentamos esses conteúdos que ele atribui ao ensino como processo específico a alcançar num local específico, teremos o quadro de uma escola concreta e severa; em resumo, de um reino da necessidade, e não da liberdade, para as crianças, cujo valor intrínseco e positivo consistirá justamente nessa apropriação de uma totalidade de possibilidades de domínio sobre a natureza e sobre o próprio homem (MANACORDA, 1991, p. 107).
\end{abstract}

De modo que a escola, hoje, não pode limitar-se somente ao ensino: ela deve articular ensino e educação. "Não seria concebível, hoje, uma escola que se limitasse ao ensino entendido como instrumento, como aquisição de técnicas e renunciasse aos objetivos da educação e da 'formação dos sentimentos (Idem, p. 105)". E acrescenta, com base em Lênin, "a escola separada da política é uma mentira e uma hipocrisia, se é verdade que toda a escola é ideologicamente orientada (...), é também verdade que, tanto mais por esta razão, se torna necessário determinar de que modo e até que ponto esse tipo de compromisso social da escola deva ou possa realizar-se" (Ibidem, p. 105).

Ensino e educação, em Marx, estão articulados a uma única ciência: a ciência do homem que produz sua existência através do trabalho e da indústria, de tal modo que ciências naturais e ciências humanas formam uma unidade.

Não pode haver, portanto, para Marx, uma ciência natural e uma ciência
do homem separadas, porque a relação do homem com a natureza firma-
se na indústria, isto é, na sua atividade vital, produtiva (ou melhor, na
atividade produtora da vida) e esta é, ao mesmo tempo, uma história
natural e uma história humana. Não há, portanto, uma interrupção entre o
homem e a natureza. O homem cresce juntamente com a natureza
(concresce) justamente porque sua indústria, sua atividade produtiva, é
uma atividade que se relaciona universalmente com a natureza, de modo
livre, consciente e voluntário, para transformá-la e, nela, transformar a si
mesmo. Nesta perspectiva, Marx postula a exigência de uma história
natural que seja também história humana, de uma ciência natural que seja
também uma ciência do homem, pois não deverá existir mais do que uma
única ciência (...). O reino da liberdade é o reino das vocações
individuais, das atividades desinteressadas, não imediatamente
produtivas, que são, para Marx, parte integrante da pessoa humana e,
portanto, da sua formação ou educação (Ibidem, p. 107).

Gramsci foi o pensador marxista, em nosso entender, que melhor expressou a relação trabalho e educação escolar. Na escola elementar, dizia, não é necessário os alunos trabalharem na fábrica para educarem-se para o trabalho. É contra uma educação profissional que bitole para uma formação técnica e unilateral. Ao contrário, defende uma educação que desenvolva nas crianças "a capacidade de trabalhar industrialmente, num processo escolar coordenado com a fábrica, mas dela autônomo" (GRAMSCI, apud MANACORDA, 1991, p. 137).

Em concordância com Marx, Gramsci mantém a unidade do "conceito e o fato" do trabalho como "princípio educativo imanente da escola elementar" tendo como base o equilíbrio entre ordem natural e ordem social pela mediação do trabalho no processo de humanização da natureza. Tal integração entre educação e ensino ocorre da seguinte forma: 
O conteúdo educativo do ensino de base tem dois elementos educativos fundamentais: 'as primeiras noções de ciências naturais e as noções de direitos e deveres do cidadão'. São exatamente esses elementos 'culturais' que determinam a natureza e a função educativa do trabalho no pensamento de Gramsci, na medida em que as leis da sociedade ('civil e estatais', diz ele) 'colocam os homens na posição mais adequada para dominar as leis da natureza', isto é, 'para facilitar seu trabalho, que é o modo específico do homem participar ativamente da vida da natureza para transformá-la e socializá-la'. É esta a premissa teórica da proposta gramsciana de organização de uma 'escola única inicial de cultura geral, humanística, formativa que harmonize precisamente o desenvolvimento da capacidade de trabalho intelectual' (MANACORDA, 1991, p. 137).

Do mesmo modo, Pistrak (2003), ao desenvolver o "método do complexo" em relação ao trabalho na escola, afirma: "nem o trabalho e nem os conhecimentos são fins em si mesmos. O que determina o trabalho e o conhecimento são os objetivos gerais: a educação do ser humano necessário para a sociedade" (p. 114). Ao referir-se ao trabalho da fábrica, enfatiza a "educação social". É preciso considerar a fábrica em suas relações amplas e complexas. Fazer a junção da técnica e da economia. No estudo: considerar a energia, a geografia econômica, questões econômicas e políticas, as matérias-primas, as máquinas-ferramenta, a questão do produto (venda, consumo, mercados). As relações de trabalho (salário e condições de vidas dos operários): "É preciso imaginar a fábrica como o centro de uma ampla e sólida teia de aranha, de onde partem inumeráveis fios ligados entre si de maneira a formar os nós múltiplos da vida" (PISTRAK, 2003, p. 78).

Também faz a crítica ao ensino da ciência pura: "Não se trata de negar o ensino dos conhecimentos científicos, mas de negar os conhecimentos científicos da ciência pura que não possuem aplicabilidade à vida. A finalidade da escola é a "educação social" (idem, p. 119).

Portanto, na pedagogia marxista articula-se ensino e educação com a finalidade de formação de homens "onilateriais". É a formação do homem completo, cidadão dirigente, com formação intelectual, tecnológica e do corpo, tal como foi proposto por Marx.

Por educação entendemos três coisas:

1.Educação intelectual.

2. Educação corporal, tal como a que se consegue com os exercícios de ginástica e militares.

3. Educação tecnológica, que recolhe os princípios gerais e de caráter científico de todo o processo de produção e, ao mesmo tempo, inicia as crianças e os adolescentes no manejo de ferramentas dos diversos ramos industriais.

(...) Esta combinação de trabalho produtivo pago com a educação intelectual, os exercícios corporais e a formação politécnica elevará a classe operária acima dos níveis das classes burguesa e aristocrática. (Marx, 1992, pp. 60-61).

É o que também afirma Manacorda com base em Gramsci:

O objetivo da escola única: proporcionar às crianças um desenvolvimento harmonioso de todas as atividades (...). "Creio - escreve, referindo-se aos filhos - que, em cada um deles, manifestam-se todas as tendências, como 
nas demais crianças, seja para a prática, seja para a teoria e a fantasia e que, por isso, seria justo orientá-los, nesse sentido, a um equilíbrio harmonioso de todas as faculdades intelectuais e práticas, que poderão especializar-se em seu devido tempo sobre a base de uma personalidade vigorosamente formada em sentido pleno e integral (MANACORDA, 1991, pp. 139 e 140).

E, mais especificamente, em relação ao ensino, sua finalidade, o trabalho industrial tem como princípio educativo, para Gramsci superar a necessidade em vista da construção da liberdade. Concordamos com Nosella quando este afirma ser a escola de Gramsci a "escola da liberdade".

Trata-se (...) de uma escola da liberdade, isto é, de uma escola onde se ensina a ser livre. Esta liberdade, assim como a fantasia, não é abstração, mas é historicamente determinada. Por isso deve ser ensinada. Não se trata da liberdade metafísica pela qual a alma se liberta dos corpos; nem da liberdade do pecado na entrada para o céu; tão pouco é a liberdade romântica do bom selvagem ou do índio imaginário; nem mesmo a liberdade da fantasia do não-trabalho absoluto. É a liberdade forjada no e pelo trabalho moderno, administrado pelo próprio trabalhador o qual produz e define a política de produção e distribuição. É a liberdade do corpo que incorporou - com disciplina - a técnica e por esta se expressa mais profunda e plenamente. Assim como me ocorre com esta caneta; de instrumento estranho e hostil, passou a ser, com disciplina e metodicidade, um instrumento de cópia das palavras alheias, depois se tornou instrumento para a manifestação dos meus pensamentos mais elementares e, finalmente, passou a ser a forma técnica de realização e expressão de minha intimidade, de minha inspiração, de minha liberdade. A caneta representa instrumentalmente o mundo do trabalho, princípio pedagógico e concretização da liberdade humana. (NOSELLA, 1992, pp. 124-125)

Está aí, portanto, a possibilidade do ensino, na educação formal, ser um processo educativo pela mediação do princípio educativo do trabalho desde que realizado pelo método do materialismo histórico dialético. Ensino é educação.

\section{Considerações finais}

Vimos que, para superar a "falta de limites", referindo-nos, aqui, ao expresso por Gramsci como "mamíferos de luxo", faz-se necessária uma educação para o "trabalho concreto", desde a infância. A partir do pressuposto de que aquilo que os homens são coincide com o que e como produzem (MARX, 2007), é possível destacar que não há possibilidade de educar para o trabalho quando os pais e responsáveis por essas crianças não têm sequer o direito ao trabalho (mesmo que alienado). Desestruturação familiar significa não somente a desorganização da instituição "família" (que é sempre histórica) no sentido moral, mas também das condições materiais de vida. Para sobreviver, parte dessas crianças realiza qualquer trabalho, no sentido da negatividade ${ }^{6}$ do termo: coleta de lixo, roubo, trabalho para o tráfico etc. e, neste processo de trabalho alienado, elas são educadas pelo "meio" (lógica do capital: dominação, exploração, enfim, relativização e negação do valor do ser humano). Eis aqui, em nosso entender, uma das causas da falta de limites de milhares de crianças brasileiras que vivem na miséria. 
Por outro lado, para a maioria dos trabalhadores assalariados, submetidos a uma tendência de ampliação do trabalho flexível, precarizado, temporário, vivencia-se cada vez mais o que Sennett (2004) denomina de "corrosão do caráter". Na base da corrosão do caráter está a corrosão do trabalho alienado. Numa sociedade em que "não há tempo longo", de instabilidade e incerteza, os trabalhadores são levados a uma perda de controle no trabalho que se transfere para a vida emocional e familiar. Traços do caráter, como compromisso mútuo, confiança e lealdade, não se efetivam porque não há tempo longo que possibilite a formação de hábitos que vão formar a segunda natureza.

Para a pedagogia marxista, o fenômeno da "falta de limites" dos alunos não é um problema individual, próprio da essência humana. Ao contrário, os alunos constituem suas individualidades a partir das relações com a natureza (práxis) e com os outros. E as relações sociais predominantes são as relações do modo de produção capitalista. O próprio modo de produção capitalista educa de forma coercitiva, apresentando um "mundo" de facilidades no qual tudo parece ser interessante, agradável e prazeroso. Naturaliza-se a lógica da mercadoria, do consumismo e, principalmente, da educação para o trabalho assalariado para a maioria da população, com um tipo específico de disciplina.

Portanto, o problema da "falta de limites" dos alunos perpassa as classes sociais. A burguesia tende a educar seus filhos como "mamíferos de luxo", negando a eles o dever ao trabalho concreto criador de valores de uso. As crianças crescem acreditando ser natural viverem a custa do trabalho dos outros. A classe trabalhadora tende a educar seus filhos a partir da educação burguesa, mas se vê enredada pela contradição entre um mundo de possibilidades e a realidade concreta da precarização de sua condição social, produzindo em seus filhos a frustação e inferiorização. Daí, talvez, uma explicação para a revolta ou resistência desses alunos ao processo de escolarização.

Nas condições dadas, a pedagogia marxista preconiza para todas as crianças uma educação que tenha no trabalho concreto sua centralidade; parte do pressuposto de que o homem não nasce homem, torna-se homem a partir do aprendizado do trabalho. Este aprendizado é um processo coercitivo que exige severidade para a formação dos hábitos. Este educar deve ser feito com base numa filosofia do "meio-termo" (nem excesso e nem falta, ser severo de forma carinhosa). É a partir da centralidade do trabalho concreto que se produz a segunda natureza, ou seja, o ser humano que, dependendo das condições sociais em que vive, torna-se respeitoso, conhecedor do valor de seu trabalho e do trabalho dos outros.

A "falta de limites" dos alunos pode também ser decorrência de uma educação espontaneísta, da renúncia dos pais ou responsáveis em educar. Renúncia que pode estar relacionada, de um lado, às exigências do mercado de trabalho que absorve todo o tempo e, de outro, à falta de conhecimento, oscilando-se entre uma educação espontaneísta e uma educação autoritária. Abandonadas ao "meio" (modo de produção capitalista), as crianças são educadas pelo meio de forma coercitiva, pois absorvem tudo o que lhes é interessante, agradável e que lhes dá prazer, negando o esforço, a disciplina e o trabalho. Não sabem dar "valor" às coisas. Não possuem referências e caem num relativismo de valores, entre os quais a falta de respeito pelos outros, inclusive pelos professores. A lógica do fetichismo da mercadoria produz a coisificação das relações humanas.

Com esta breve compreensão de como se produz a segunda natureza, que, uma vez produzida, é difícil ser modificada, retomamos a questão apontada na introdução: Como educar e ensinar alunos que possuem, de certa forma, uma "segunda natureza" - no caso, "sem limites" - já formada, ou, em que medida é possível reeducar e como fazê-lo a partir das condições dadas? Eis aí o desafio. 
Certamente, nas condições precárias da rede pública brasileira, é tarefa quase impossível. As condições precárias, segundo Saviani (2003) são a ausência de um sistema nacional de educação, "a questão material da organização do sistema das escolas" e o problema da descontinuidade que, juntos, constituem-se desafios para a prática.

$\mathrm{Na}$ raiz da precariedade está o problema do financiamento da educação pública. Saviani (2008) propõe um investimento em torno de $8 \%$ do PIB destinado à educação e que ela fosse considerada como uma necessidade social. Com tais recursos seria possível organizar as escolas a partir da pedagogia marxista, o que possibilitaria criar condições objetivas para viabilizar o reeducar. Mas a concretização desta proposta somente ocorrerá mediante a luta dos trabalhadores pela implantação de outra política educacional que coloque "freios ao capital" (Marx, 2004).

Finalizo com esta proposição de Marx sobre a necessidade de uma legislação que defenda aos filhos dos trabalhadores uma educação politécnica.

Isto só será possível mediante a transformação da razão social em força social e, nas atuais circunstâncias, só podemos fazê-lo através das leis gerais impostas pelo poder do Estado. Impondo tais leis, a classe operária não tornará mais forte o poder governamental. Ao contrário, fará do poder dirigido contra elas, seu agente. O proletariado conseguirá então, com uma medida geral, o que tentaria em vão com muitos esforços de caráter individual (MARX, 1992, p. 60).

Enquanto essa transformação não ocorre na politica educacional brasileira, ou ocorre de forma muito limitada - "pedagogia dos resultados", em que certas conquistas se realizam pela concepção produtivista - os professores estão em sala de aula com o problema de crianças que possuem uma segunda natureza não disciplinada para o trabalho do estudo. Penso que a socialização dos conhecimentos produzidos pela pedagogia marxista sobre o processo de formação da segunda natureza a partir do "trabalho pedagógico" possibilita, a esses professores, "um maior grau de consciência, ou seja, de conhecimento, compreensão da realidade da qual nós, seres humanos, somos parte e na qual atuamos teórica e praticamente" (RIBEIRO, 2001, p. 29). Se há a necessidade de reeducar a segunda natureza dos alunos, há também a necessidade de reeducar o professor, ambos sínteses das relações sociais capitalistas.

\section{Bibliografia}

ARISTÓTELES. Política. São Paulo: Nova Cultural, 1999 (Coleção os Pensadores).

ARISTÓTELES. Ética a Nicômaco. 4. ed. São Paulo: Nova Cultural, 1991 (Os pensadores; v. 2).

ENGELS, F. Sobre o papel do trabalho na transformação do macaco em homem. In: ANTUNES. Ricardo (org.). A dialética do trabalho: escritos de Marx e Engels. São Paulo: Expressão Popular, 2004.

FRIGOTTO, Gaudêncio. A dupla face do trabalho: criação e destruição da vida. In: FRIGOTTO, G.; CIAVATTA, M. (Orgs.). A experiência do trabalho e a educaçào básica. Rio de Janeiro: DP\&A, 2002.

GOERGEN, Pedro. Ética e educação: o que pode a escola? In: LOMBARDI, José Claudinei, GOERGEN, Pedro (orgs.). Ética e Educação: reflexões filosóficas e históricas. Campinas, SP: Autores Associados: HISTEDBR, 2005.

GRAMSCI, Antonio. Cartas do Cárcere. Vol. 1. Rio de Janeiro: Civilização Brasileira, 1999.

GRAMSCI, Antonio. Cadernos do cárcere. Vol. 2. Rio de Janeiro: Civilização Brasileira, 2000 
LIBÂNEO, José Carlos. Alguns aspectos da política educacional do governo Lula e sua repercussão no funcionamento das escolas. Revista HISTEDBR On-line, Campinas, n.32, p. 168-178, dez.2008 - ISSN: 1676-2584.

MAKARENKO, Anton Semiónovitch. Poema pedagógico. São Paulo, SP: Brasiliense, 2005.

MAKARENKO, Anton Semiónovitch. O livro dos pais. Lisboa: Livros Horizonte, 1976 V. 1 e 2.

MAKARENKO, Anton. A família e a educação dos filhos. In: LUEDEMANN, Cecília da Silveira. Anton Makarenko: vida e obra - a pedagogia na revolução. São Paulo: Expressão Popular, 2002.

MANACORDA, Mario Alighiero. O princípio educativo em Gramsci. Porto Alegre: Artes Médicas, 1990.

MANACORDA, Mario Alighiero. Marx e a pedagogia moderna. São Paulo: Cortez e Autores Associados, 1991.

MARX, Karl . Instruções aos delegados do conselho central provisório. In: MARX \& ENGELS. Textos sobre educação e ensino. São Paulo: Editora Moraes, 1992.

MARX, Karl. Contribuição à Crítica da Economia Política. São Paulo: Martins Fontes, 1987.

MARX, Karl. O Capital: crítica da economia política. 17. ed. Rio de Janeiro: Civilização Brasileira, 1999. Livro 1. v. 1 e 2.

MARX, Karl. Critica ao Programa de Gotha. In: ANTUNES. Ricardo (org.). A dialética do trabalho: escritos de Marx e Engels. São Paulo: Expressão Popular, 2004.

MÈSZÀROS, Istvan. Marx: a teoria da alienação. São Paulo: Boitempo, 2006.

MÈSZÀROS, Istvan. A educação para além do capital. São Paulo: Boitempo, 2005.

NOSELLA, Paolo. A escola de Gramsci. Porto Alegre: Artes Médicas, 1992.

PISTRAK, M. Fundamentos da escola do trabalho. São Paulo: Expressão Popular, 2003.

RIBEIRO, Maria Luisa Santos. Educação escolar: que prática é essa? Campinas, SP: Autores Associados, 2001.

SAVIANI, Dermeval. Escola e democracia. São Paulo: Cortez Editora/Autores Associados, 1987.

SAVIANI, Dermeval. Sobre a concepção de politecnia. RJ, EPSJV/FIOCRUZ, 1989.

SAVIANI, Dermeval. Os saberes implicados na formação do educador. In: BICUDO, Maria A, Viggiani, SILVA JR, Celestino (orgs.). Formação do educador. São Paulo: UNESP, 1996.

SAVIANI, Dermeval. Pedagogia Histórico-Crítica: Primeiras Aproximações. Campinas, SP: Autores Associados, 2003.

SAVIANI, Dermeval. Da nova $L D B$ ao FUNDEB: por uma outra política educacional. Campinas, SP: Autores Associados, 2008.

SAVIANI, Dermeval. "Modo de produção e a pedagogia histórico-crítica". Germinal: Marxismo e Educação em Debate, Londrina, v. 1, n. 1, p. 110-116, jun. 2009. Acesso eletrônico pelo seguinte link: http://www.uel.br/revistas/uel/index.php/germinal/article/view/2649/2303. Acesso em 20 de outubro de 2010.

SAVIANI, Dermeval. Marxismo e educação. In: Revista Princípios. São Paulo, 82 (37/45), p. 37-45, dezembro/2005.

SAVIANI, Dermeval. Trabalho e educação: fundamentos ontológicos e históricos. In: Revista Brasileira de Educação v. 12 n. 34 jan./abr. 2007, p. 152-180.

SNYDERS, Georges. Pedagogia progressista. Coimbra: Livraria Almeida, 1974. 
SNYDERS, Georges. Escola, Classe e Luta de Classes. 2a ed. Lisboa - Portugal: Moraes, 1981.

SENNETT, Richard. A corrosão do caráter: as consequencias pessoais do trabalho no novo capitalismo. Rio de Janeiro: Record, 2004.

SUCHODOLSKI, Bogdan. A pedagogia e as grandes correntes filosóficas: a pedagogia da essência e a pedagogia da existência. Lisboa: Livros Horizonte, 2000.

TEIXEIRA. Anísio. Pequena introdução à filosofia da educação: a escola progressiva ou a transformação da escola. 6. ed. Rio de Janeiro: DP\&A, 2000.

VÁZQUEZ, Adolfo Sánchez. Filosofia da práxis. Rio de Janeiro: Paz e Terra, 1968.

Notas:

${ }^{1}$ Professor da Universidade Estadual do Oeste do Paraná - Campus de Francisco Beltrão-PR. E-mail: zanellazl@hotmail.com

${ }^{2}$ Entendemos por pedagogia marxista as contribuições originárias do pensamento de Marx $(1999,2004)$, Engels (2004), Marx e Engels (1976), Gramsci (1999, 2000, Makarenko (1976, 2002 e 2005) e Pistrak (2003). Destacamos as contribuições do pensamento contemporâneo de Manacorda (1990 e 1991), Snyders (1974 e 1981) e, do Brasil, a contribuição de Saviani (2003, 2005 e 2007). Salientamos que este é um recorte, uma vez que a teoria marxista de educação é bem mais ampla.

${ }^{3}$ Em cursos de capacitação para professores da educação básica da rede pública em municípios da região Sudoeste do Paraná, nos últimos anos, verificamos que parece haver um consenso entre estes profissionais sobre a manifestação crescente entre parte dos alunos do fenômeno denominado por eles de "falta de limites" (alunos agressivos, inquietos, sem responsabilidades, que não respeitam o educador e nem seus colegas). A resistência à disciplina de estudo e ao conhecimento escolar intensifica-se. Os professores vivenciam a "angústia do labirinto". Há uma "queixa" em forma de desabafo, uma espécie de grito de socorro, em que os professores se veem perdidos, sem saber que caminho seguir e como proceder diante da problemática. Constata-se, em muitos casos, a perda de sentido do trabalho docente e resulta daí um sentimento de frustração, tristeza, desânimo e impotência ao ponto de muitos professores ficarem doentes.

${ }^{4}$ No volume I da obra $O$ Capital (1999) Marx assim se refere ao filósofo Aristóteles: "grande pesquisador" (p. 23). O fato de Aristóteles ter produzido uma filosofia a partir dos interesses da sociedade grega escravocrata não invalida sua contribuição filosófica. O método dialético materialista de Marx possibilita a incorporação por superação dos conhecimentos clássicos e científicos.

${ }^{5}$ Embora a pedagogia de Makarenko tenha sido executada e sistematizada na primeira metade do século XX com as crianças infratoras da sociedade soviética, entendemos, resguardadas as devidas proporções do contexto histórico, que esta mesma pedagogia apresenta princípios educativos "concretos" válidos para os educadores e as crianças de nosso tempo.

${ }^{6}$ Segundo Manacorda (1991), o "trabalho", em Marx, é "uma expressão negativa", quando historicamente determinado pela "sociedade fundada sob a propriedade privada dos meios de produção e a teoria ou ideologia que a expressa" (p. 44). Conclui, citando Marx, que, sob esta determinação, "o trabalho é o homem que se perdeu a si mesmo" (p. 45).

Recebido em: $\quad$ 10/12/10

Aprovado em: $\quad 22 / 03 / 11$ 